\title{
Radial Artery and Saphenous Vein Grafts in Coronary Artery Bypass Surgery Comparison in Terms of Patient Symptoms
}

\author{
Tugra Gencpinar1 ${ }^{*}$, Koray Aykut², Gokhan Albayrak², Umut Ayoğlu1, Muzaffer Yilmaz ${ }^{1}$, \\ Kadir Sagdic ${ }^{1}$, Mustafa Emmiler ${ }^{1}$ \\ ${ }^{1}$ Cardiovascular Surgery Clinic, Education and Research Hospital, Antalya, Turkey \\ ${ }^{2}$ Department of Cardiovascular Surgery, Izmir University, Izmir, Turkey \\ Email: uugra01@yahoo.com, drkaykut@hotmail.com, albayrakg@hotmail.com, drraifumut@hotmail.com, \\ savan64@hotmail.com, sagdick@tnn.net, dremmiler@yahoo.com
}

Received 6 February 2014; revised 6 March 2014; accepted 14 March 2014

Copyright (C) 2014 by authors and Scientific Research Publishing Inc.

This work is licensed under the Creative Commons Attribution International License (CC BY). http://creativecommons.org/licenses/by/4.0/

(c) (i) Open Access

\section{Abstract}

Background: The aim of this study is to compare radial artery with saphenous vein grafts which are widely used for coronary bypass, from views of patients' satisfaction and postoperative findings. Methods: 42 isolated coronary bypass (CABG) patients performed during November 2012April 2013 are included in the study. 30 days after the operation, in patients who had both RA and SV removal made responses to a questionnaire form which included 6 questions about symptoms of extremity. Results: After analyzing the responses and physical examination, there was no difference in terms of quality of life and usefulness of the extremity for daily use between two grafts. 2 patients $(2 \%)$ have wound infection on the saphenous vein incision and additional surgical procedure was performed and a scar tissue has occurred. There was no statistically significance between uncomfortable symptoms and demographic data. Conclusion: Our study suggested that RA graft using showed a bit more comfortable and suitable effect against SV in our patients. We think that radial arterial grafts should be used more widely in coronary surgery with selected patients.

\section{Keywords}

Radial Artery, Saphenous Vein, Coronary Artery Bypass Grafting

\section{Introduction}

Coronary artery bypass graft (CABG) is a superior management approach for severe coronary artery disease.

${ }^{*}$ Corresponding author.

How to cite this paper: Gencpinar, T., et al. (2014) Radial Artery and Saphenous Vein Grafts in Coronary Artery Bypass Surgery Comparison in Terms of Patient Symptoms. World Journal of Cardiovascular Surgery, 4, 43-46. 
The left internal thoracic artery is considered to be the best conduit for CABG [1]. However, the preferred conduit between the radial artery (RA) and saphenous vein (SV) remains controversial. The satisfaction of patients with CABG surgery is dependent on harvesting of the selected conduit. There is a relative paucity of data on long term hand and leg function after greft harvesting [2]. Previous studies reported minor complications such as pain, infection, scar and neurologic complications [2] [3]. The present meta-analysis aims to establish long time guality of life outcomes comparing the RA with SV conduits. 42 isolated coronary bypass(CABG) patients performed are included in the study. 30 days after the operation, in patients who had both RA and SV removal answered a questionnaire form including 6 questions about symptoms of extremity (2 questions about quality of life and 3 questions for wound healing). Demografic data and comorbidities were analyzed (Table 1). The present study aimed to compare comfort with discomfort of these two conduits at mid-term follow up.

\section{Patients}

In the time period from November 2012 to April 2013, forty-two cases (31 males and 11 females), who have undergone isolated CABG in the department of cardiovascular surgery, were included. Informed consent was obtained from each patient. LITA conduit, RA and SVG were used in all cases. Intra-aortic balloon counterpulsation (IABP) was introduced in one case during weaning from CPB. Mean age patients was $56.4 \pm 7.8$. Comorbidities related to the patient group were, diabetes mellitus in 17 cases, hypertension in 18 cases and smoking in 4 cases (Table 1). Standart anticoagulant therapy (acetil-salicilic acide $100 \mathrm{mg} /$ day and clopidogrel $75 \mathrm{mg}$ /day peroral) were given to all patients in the postoperative period.

\section{Exclution Criterias}

Patients with stroke, transient ischemic attack, peripheral vascular disease or muscle disease, trauma, shock, malnutrition, pregnancy, liver diseases, dialysis dependent renal failure and neoplasies were excluded.

\section{Materials and Methods}

All harvesting procedures were performed with standard no-touch technigue and endoscopic techniques were not used. "Allen Test" had been done before RA harvesting and transcutaneus pulse oximeter used. Color Doppler Ultrasound was used before SVG and RA harvesting. The saphenous vein was not suitable for grafting in 2 patients' leg due to Doppler examination. The grafts were harvested with scissors and hemoclips used for bleeding. The grafts were protected inside of Papaverine $(1.0 \mathrm{mmol} / \mathrm{L})$ mixed with heparinized blood. Also heparinized blood was injected intraluminally into the RA and SVG grafts after harvesting. RA was commonly used for the obtuse marginal branches and/or the posterior descending coronary artery.

Statistical analysis was performed with "Statistical Package for Social Sciences”(SPSS-15 Chicago, IL, USA) and Software Excel (Microsoft-USA). Continuous variables were expressed as mean and standard deviation. The approprity to normal expedition had been checked. Chi-square and Fischer tests were used to determine independent predictors. If the $\mathrm{p}$ value was $<0.05$, the results were considered significant.

\section{Results}

Saphenous veins are widely used in coronary bypass grafting operations due to the ease of preparation. After saphenous vein graft harvesting, especially obese female patients postoperatively bears wound healing problems. Pain, numbness, swelling, itching, discoloration, extremity function loss, scar, infection, additional surgical interventions, difficulties with daily tasks, effect on life were evaluated in both groups. There was no statistically significant difference between two groups ( $>$ > 0.05) (Table 2). As we have demonstrated in our study, the radial artery graft in appropriate cases can be used with the same cosmetic results with SVG.

\section{Discussion}

CABG results in excellent long term survival [4]. RA conduit was reported in 1973 by Carpentier. It was not popularized until the 1990s, when antispasmodic medications and improved harvesting techniques were routinely used to prevent early spasm and occlusion. [2] [4] The use of SV was pioneered by Favaloro in early years of CABG [3] [4]. Studies shows that patients with hypertension, diabetes, peripheral vascular disease, 
Table 1. Demographic profile of the patients.

\begin{tabular}{cc}
\hline No. of patients & 42 \\
\hline Sex & F: $11(26.2 \%)$ M: $31(73.8 \%)$ \\
Age & $56.4 \pm 7.8$ \\
Diabetes Mellitus & $17(41.5 \%)$ \\
HbA1c (\%) & $6.2 \pm 1.1$ \\
Smoking & $18(42.8 \%)$ \\
\hline
\end{tabular}

Table 2. Survey results.

\begin{tabular}{lccc}
\hline & $\begin{array}{c}\text { Radial Artery } \\
\text { Harvesting }\end{array}$ & $\begin{array}{c}\text { Saphenous Vein } \\
\text { Harvesting }\end{array}$ & p value \\
\hline 1. Pain & $(12 \%)$ & $(12 \%)$ & $\mathrm{p}>0.05$ \\
2. Numbness & $(21 \%)$ & $(19 \%)$ & $\mathrm{p}>0.05$ \\
3. Swelling & $(12 \%)$ & $(15 \%)$ & $\mathrm{p}>0.05$ \\
4. Itching & $(17 \%)$ & $(27 \%)$ & $\mathrm{p}>0.05$ \\
5. Discoloration & $(14 \%)$ & $(14 \%)$ & $\mathrm{p}>0.05$ \\
6. Extremity function loss & - & $(2 \%)$ & $\mathrm{p}>0.05$ \\
7. Scar & - & $(5 \%)$ & $\mathrm{p}>0.05$ \\
8. Infected wound & - & $(5 \%)$ & $\mathrm{p}>0.05$ \\
9. Additional surgical intervention & - & $(5 \%)$ & $\mathrm{p}>0.05$ \\
10. Difficulties with daily tasks & $(7 \%)$ & $(7 \%)$ & $\mathrm{p}>0.05$ \\
11. Effect on life & $(10 \%)$ & $(10 \%)$ & $\mathrm{p}>0.05$ \\
\hline
\end{tabular}

aortic disease and stroke have higher risk for coronary artery disease especially in elderly patients [5]. Competitive flow can cause graft failure in patients with less severe coronary artery disease. SV and RA are the most commonly used grafts in combination with the left internal mammary artery(LITA) for conventional CABG. [6]

Arterial conduits including RA have high patency, resulting in better long term survival in comparison with SV graft. [7]. Guidelines show that coronary stenosis of $85 \%$ or more lesions, long-term RA graft patency rates are higher. [8] There is a benefit from active endothelium of the RA and LITA conduits (producing vasoactive and endothelial progenitor substances) [7] [8]. The presence of a smooth muscle layer in the arterial wall helps the conduit to adjust its caliber to the coronary flow in the native vessels, creating less turbulance at the distal anastomosis [8] [9]. In addition, male elderly patients and patients with diabetes mellitus were reported having more benefit from RA. Also the harvesting technique, storage solution, size, severity of stenosis, distal runoff coronary artery are very important for long-term graft patency [10]-[12]. After the operation, the patients' satisfaction is important based on higher guality of life [11]-[13]. This paper describes a recent development of choosing the grafts. In the postoperative period, complications at the incision site are very effective in reducing hospital stay, and hospital costs and in increasing patients' comfort and satisfaction.

Our study examines the effect of conduit type on the patients' comfort who underwent elective CABG. RA harvesting was comfortable and suitable like SV harvesting. Also, RA is a good alternative for saphenous vein when it is not suitable for grafting due to Doppler examination.

\section{Conclusion}

This benefit of RA may contribute to better comfort of the patients who undergo coronary revascularization with excellent cumulative patency. RA can be used more widely in CABG. Larger studies are required to corroborate these findings.

\section{Disclosure}

The authors declare no conflict of interest. 


\section{References}

[1] Zacharias, A., Habib, R.H., Schwann, T.A., Riordan, C.J., Durham, S.J. and Shah, A. (2004) Improved Survival with Radial Artery Versus Vein Conduits in Coronary Bypass Surgery with Left Internal Thoracic Artery to Left Anterior Descending Artery Grafting. Circulation, 109, 1489-1496. http://dx.doi.org/10.1161/01.CIR.0000121743.10146.78

[2] Tatoulis, J., Royse, A.G., Buxton, B.F., Fuller, J.A., Skillington, P.D., Goldblatt, J.C., et al. (2002) The Radial Artery in Coronary Surgery: A 5-Year Experience-Clinical and Angiographic Results. The Annals of Thoracic Surgery, 73, 143-148. http://dx.doi.org/10.1016/S0003-4975(01)03290-8

[3] Tranbaugh, R.F., Diminitrova, K.R., Friedmann, P., Geller, C.M., Harris, L.J., Stelzer, P., et al. (2010) Radial Artery Conduits Improve Long-Term Survival after Coronary Artery Bypass Grafting. The Annals of Thoracic Surgery, 90, 1165-1172. http://dx.doi.org/10.1016/j.athoracsur.2010.05.038

[4] Tatoulis, J., Buxton, B.F., Fuller, J.A., Meswani, M., Theodore, S., Powar, N., et al. (2009) Long-Term Patency of 1108 Radial Arterial-Coronary Angiograms over 10 Years. The Annals of Thoracic Surgery, 88, 23-30. http://dx.doi.org/10.1016/j.athoracsur.2009.03.086

[5] Athanasiou, T., Saso, S., Rao, C., Vecht, J., Grapsa, J., Dunning, J., et al. (2011) Radial Artery Versus Saphenous Vein Conduits for Coronary Artery Bypass Surgery: Forty Years of Competition-Which Conduit Offers Better Patency? A Systematic Review and Meta-Analysis. European Journal of Cardio-Thoracic Surgery, 40, 208-220. http://dx.doi.org/10.1016/j.ejcts.2010.11.012

[6] Collins, P., Webb, C.M., Chong, C.F. and Moat, N.E. (2008) Radial Artery Versus Saphenous Vein Patency Randomized Trial: Five-Year Angiographic Follow-Up. Circulation, 117, 2859-2864. http://dx.doi.org/10.1161/CIRCULATIONAHA.107.736215

[7] Hayward, P.A. and Buxton, B.F. (2011)The Radial Artery Patency and Clinical Outcomes Trial: Design, Intermediate Term Results and Future Direction. Heart, Lung and Circulation, 20, 187-192. http://dx.doi.org/10.1016/j.hlc.2011.01.001

[8] Deb, S., Cohen, E.A., Singh, S.K., Une, D., Laupacis, A. and Fremes, S.E. (2012) Radial Artery and Saphenous Vein Patency More than 5 Years after Coronary Artery Bypass Surgery: Results from RAPS (Radial Artery Patency Study). Journal of the American College of Cardiology, 60, 28-35. http://dx.doi.org/10.1016/j.jacc.2012.03.037

[9] Desai, N.D., Cohen, E.A., Naylor, C.D. and Fremes, S.E. (2004) A Randomized Comparison of Radial-Artery and Saphenous-Vein Coronary Bypass Grafts. The New England Journal of Medicine, 351, 2302-2309. http://dx.doi.org/10.1056/NEJMoa040982

[10] Tranbaugh, R.F., Dimitrova, K.R., Friedmann, P., Geller, C.M., Harris, L.J., Stelzer, P., et al. (2012) Coronary Artery Bypass Grafting Using the Radial Artery: Clinical Outcomes, Patency, and Need for Reintervention. Circulation, 126, S170-S175. http://dx.doi.org/10.1161/CIRCULATIONAHA.111.083048

[11] Habib, R.H., Schwann, T.A. and Engoren, M. (2012) Late Effects of Radial Artery versus Saphenous Vein Grafting in Patients Aged 70 Years or Older. The Annals of Thoracic Surgery, 94, 1478-1484. http://dx.doi.org/10.1016/j.athoracsur.2012.05.030

[12] Goldman, S., Sethi, G.K., Holman, W., Thai, H., McFalls, E., Ward, H.B., et al. (2011) Radial Artery Grafts vs Saphenous Vein Grafts in Coronary Artery Bypass Surgery: A Randomized Trial. The Journal of American Medical Association, 305, 167-174. http://dx.doi.org/10.1001/jama.2010.1976

[13] Gaudino, M., Prati, F. and Possati, G. (2006) Radial Artery Grafting. Multimedia Manual Cardio-Thoracic Surgery, 2006.

\section{Abbreviations}

RA: radial artery

$\mathrm{SV}$ : saphenous vein

CABG: coronary artery bypass grafting 